\title{
Retraction Note to: Coordination mechanism of marine ecological protection and its impact on Island tourism resources development
}

\author{
Nan Wang ${ }^{1} \cdot$ Fengwei $\mathrm{Ai}^{2}$
}

Published online: 16 December 2021

(c) Saudi Society for Geosciences 2021

Retraction Note to: Arabian Journal of Geosciences (2021) 14: 474 https://doi.org/10.1007/s12517-021-06714-2

The Editor-in-Chief and the Publisher have retracted this article because the content of this article is nonsensical. The peer review process was not carried out in accordance with the Publisher's peer review policy. The authors have not responded to correspondence regarding this retraction.

The original article can be found online at https://doi.org/10.1007/ s12517-021-06714-2.

Nan Wang

wangnan2@nbu.edu.cn

1 School of Economics and Law, School of Science and Technology, Ningbo University, Cixi 315300, Zhejiang, China

2 School of tourism and Geographical Sciences, Hulunbuir University, Hailar 021008, Inner Mongolia, China 